(>)

\title{
FILOSOFÍA Y LITERATURA
}





\section{LA AUSENCIA DE PODER}

O LA AFIRMACIÓN DE LA POTENCIA NEUTRA

DE LA LITERATURA.

REFLEXIONES

EN TORNO AL

PENSAMIENTO

LITERARIO DE BLANCHOT

LUIS ANTONIO RAMÍREZ ZULUAGA

Universidad de Antioquia

(c) $\underset{\text { (i) }}{ }$ 


\title{
LA AUSENCIA DE PODER O LA AFIRMACIÓN DE LA POTENCIA NEUTRA DE LA LITERATURA. REFLEXIONES EN TORNO AL PENSAMIENTO LITERARIO DE BLANCHOT*
}

\begin{abstract}
Resumen: a partir de la obra de Maurice Blanchot este artículo desarrolla una reflexión teórica sobre la literatura como expresión de una potencia neutra despojada de la presencia autoritaria del poder. Inicialmente se aborda la ambigüedad que Blanchot detecta entre el silencio y el murmullo presente tanto en el discurrir del lenguaje cotidiano como en la literatura, al igual que en la vacuidad del habla destinada a ordenar y a repetir las normas de la tradición. Entre esas tres formas de lenguaje, es en la literatura donde pesa más esa ambigüedad ya que en ella no hay un trasfondo de verdad o unidad. Desde esa perspectiva se pasa entonces a revisar la noción de desobramiento como una operación en la cual la literatura debe rechazar cualquier poder que subsista en ella para afirmar finalmente la potencia neutra e impersonal de la obra.
\end{abstract}

Palabras clave: Maurice Blanchot, Pensamiento literario, Poética, Poder, Obra y autor.

\section{THE ABSENCE OF POWER OR THE AFFIRMATION OF THE NEUTRAL POWER OF THE LITERATURE. REFLECTIONS ON BLANCHOT'S LITERARY THOUGHT}

\begin{abstract}
From the work of Maurice Blanchot, this article develops a theoretical reflection on the literature as an expression of a neutral power stripped of the authoritarian presence of power. Initially addresses the ambiguity that Blanchot detects between silence and the murmur present both in the course of everyday language and literature, as well as on the emptiness of speech intended to order and repeat the rules of tradition. Between these three forms of language, is in literature where it weighs more this ambiguity since in it there is an undercurrent of truth or unit. From that perspective it is then passed to reviewing the notion of desobramiento as an operation in which literature should reject any power which subsists in it to finally assert the neutral and impersonal power of the work.
\end{abstract}

Keywords: Maurice Blanchot, Literary thought, Poetics, Power, Books and writers.

Fecha de recepción: Junio 25 de 2015

Fecha de aceptación: Mayo 15 de 2016

Forma de citar (APA): Ramírez Zuluaga, L. (2016). La ausencia de poder o la afirmación de la potencia neutra de la literatura. Reflexiones en torno al pensamiento literario de Blanchot. Revista Filosofía UIS, 15 (1), 145-162, doi: http://dx.doi.org/10.18273/revfil.v15n1-2016007

Forma de citar (Harvard): Ramírez Zuluaga, L. (2016). La ausencia de poder o la afirmación de la potencia neutra de la literatura. Reflexiones en torno al pensamiento literario de Blanchot. Revista Filosofía UIS, 15 (1), 145-162.

Luis Antonio Ramírez Zuluaga: colombiano. Docente-Investigador, miembro del grupo de investigación "Cultura, Violencia y Territorio" del Instituto de Estudios Regionales de la Universidad de Antioquia. Doctor en Filosofía de la Universidad de Antioquia.

Correo electrónico: lantonio.ramirez@udea.edu.co

* Artículo de reflexión

Revista Filosofía UIS, Vol. 15, No. 1, enero-junio de 2016 pp. 145-162 


\section{LA AUSENCIA DE PODER O LA AFIRMACIÓN DE LA POTENCIA NEUTRA DE LA LITERATURA. REFLEXIONES EN TORNO AL PENSAMIENTO LITERARIO DE BLANCHOT}

\section{Introducción}

Pese a que en un momento dado (hacia 1960) Blanchot haya hablado de una responsabilidad política y una responsabilidad literaria, esa doble responsabilidad difícilmente podría compartimentarse o dividirse afirmando que una corresponde estrictamente a la política y la otra sería del dominio exclusivo de la literatura; aunque ambas puedan perfilarse como dos exigencias diferentes, ellas subsisten como un pliegue o un desdoblamiento al interior de la perspectiva blanchotiana de la literatura. Prueba de ello es lo que el mismo Blanchot anunciaba desde el texto "La literatura y el derecho a la muerte" (2007a) respecto a aquellas dos vertientes de la literatura: una donde ella sería análoga al poder del rechazo y la otra donde se sumergiría en la imposibilidad. Es con esta segunda — concebida por Blanchot como una "vertiente oscura" (Blanchot, 2007a, p. 295) - que la literatura gira hacia ese punto en que el sentido es siempre lo que escapa a toda aprehensión y a todo fin, un punto donde ella no tendría la esperanza de corregir tal fuga, sino donde mantendría ese movimiento de la obsesión del sentido, deviniendo la afirmación de un "poder impersonal" (295) en el que se manifiesta la potencia anónima del lenguaje. Sobre este tema se han desarrollado diversas hipótesis y concepciones, entre las cuales sobresale aquella de Foucault (1999), según la cual es en esa potencia que el sujeto desaparece; no obstante, de lo que se tratará aquí específicamente es de explorar cómo en Blanchot la cuestión de la potencia anónima del lenguaje contrasta inicialmente con el impoder - o el "poder sin poder" (Blanchot, 2007a, p. 293) — de la literatura y, luego, con una neutralidad impersonal. 
Dicho contraste tendrá precisamente como fuente, o marco de consideración, la tensión y la incompatibilidad del doble lenguaje dividido entre la posibilidad y la imposibilidad: de un lado se encuentra el lenguaje de dominación y energía, "de voluntad y de señorío, que desea el mundo, que quiere cumplir los deberes en el mundo [para] hacer obra útil y obra visible" (Blanchot, 1992, p. 88); y de otro lado, se tiene un lenguaje desobrante y sin poder. Cuando la literatura acoge la exigencia del primer lenguaje, ella puede correr el riesgo de aproximarse a un tono autoritario, el de aquella orden sin réplica ni contenido del amo que debe probar su poderío sobre las palabras; esa palabra es vacía, en cuanto es pronunciada para no ser escuchada, no buscando más que mandar o destinándose únicamente a repetir las normas de la vida tradicional de las sociedades más conservadoras se sirven para perpetuarse. Pero si hay un lenguaje equiparable al de un poder que persevera en su vacuidad a través del autoritarismo, también habrá otro cuya exigencia es justamente la impugnación o el borramiento de todo poder; este segundo lenguaje es el que Blanchot presenta como el reto propio de la escritura literaria y en el cual se buscará ahondar a continuación para esbozar cómo la exigencia de un rechazo radical del poder implica la necesidad de empezar a forjar un espacio de impoder.

Antes de profundizar en lo que Blanchot plantea sobre la ausencia de poder en la literatura y la potencia neutra que habría en ella, se debe advertir que el rechazo al poder nunca implicó para él la necesidad de construir una nueva teoría del poder; más bien, se empeñó en afirmar una forma paradójica de poder: "el poder de rechazo" (2006b, p. 83), la exigencia de mantener el rechazo al poder como imperativo ético y político. Tal imperativo implica, no obstante, un doble a priori de la comprensión del poder: en tanto medio para ejercer la autoridad o la dominación sobre los hombres y como posibilidad de cambiar o de edificar el mundo. Contra esa primera comprensión del poder siempre conservó un rechazo radicalidad, mientras que con respecto a la segunda trató constantemente de abrir un cuestionamiento por el que se perfila la exigencia de la literatura de responder a lo imposible, a lo que está por fuera de la posibilidad y del poder.

\section{La ambigüedad del silencio y del murmullo}

Cuando la literatura se publica — se hace pública— - y entra en el juego de la lectura y la crítica, ingresa al barullo incesante de lo cotidiano; y es justamente entre la extrema divulgación de la literatura y la extrema soledad del escritor que Blanchot reconoce la riqueza y la miseria de la literatura contemporánea; al respecto, él afirma: 
Hoy en día el escritor, creyendo bajar a los infiernos, se contenta con bajar a la calle [...] porque el profundo rumor original -allí donde se dice algo pero sin palabra, donde se calla algo pero sin silencio- no deja de parecerse a la palabra no parlante, la audición mal oída y siempre al oído, que son "el espíritu" y la "vía" públicos (1992, p. 280).

En esta cercanía entre el rumor cotidiano y la literatura, puede encontrarse la paradoja de esa "palabra no parlante", aunque sea por vías muy diferentes. De un lado, se tiene el habla de la opinión pública que, en la urgencia de transmitir algo, en medio de una circulación indefinida de palabras, corre el riesgo de hacer de la palabra misma el equivalente espectral del silencio: como si se tratase de un murmullo colmado por el vacío de esas palabras que se repiten una y otra vez, donde todo parece haberse comprendido ya, no quedando nada nuevo por oír. De otro lado, puede decirse igualmente que, a su vez, la literatura podría ser acusada de convertirse — entre los ires y venires de la escritura, la lectura y la crítica - en una palabra espectral en cuanto se ve condenada a la búsqueda de un sentido que siempre parece faltar. En el fondo, tanto en la palabrería de la vida pública como en el habla incesante, errante y obsesiva de la literatura, se da una profusión o una reiteración indefinida de palabras; es por esto que, hablando de Le Bavard (El charlatán) de Louis-René des Forêts, Blanchot se preguntará: "Hablar sin comienzo ni fin, dar palabra a ese movimiento neutro que es como el todo de la palabra, ies hacer obra de charla, es hacer obra de literatura?" (2007b, p. 120).

Blanchot no se apresura en darle una primacía a la obra literaria sobre la charlatanería cotidiana, o viceversa. Él otorga más importancia a la ambigüedad de aquella "palabra no parlante" que pesa sobre ambas; aunque, según él, pesaría más sobre la primera, pues en el caso del lenguaje corriente se supone que cuando la transmisión de información llega a un malentendido, se tendría la posibilidad de limitarlo buscando la fuente de lo que se ha dicho para disipar cualquier equívoco y detener así todo rumor; mientras que en la literatura "la ambigüedad está ahí a la captura de sí misma" (2007a, p. 301), puesto que en ella el sentido general de las palabras es incierto, no haciendo más que prolongar e indeterminar infinitamente un rumor inicial. Es desde allí que Blanchot va a dar a la literatura el carácter indeterminado, pero singular, de ser "el lenguaje que se hace ambigüedad" (p. 301).

La literatura hace parte entonces de un murmullo incesante en el que está librada a los excesos de la ambigüedad; sin ser, no obstante, aquella misma reiteración de palabras de la vida cotidiana, sino más bien una especie de reverberación de lo que no cesa de susurrar, lo que no puede encerrarse en la unidad de un único sentido o de una sola comprensión. El hecho de relacionar la literatura con el movimiento indeterminado de una palabra que no tiene comienzo ni fin, implicará que ella deba abandonar toda esperanza de ser o de devenir un lenguaje original o auténtico; es así que, antes de cualquier cuestionamiento 
sobre la esencia particular de la literatura, habría que preguntarse por ese murmullo incesante en el cual parece estar atrapada. Para ello se tiene como pista la ambigüedad que Blanchot encuentra entre el murmullo y el silencio, siendo el murmullo el fondo del silencio, es decir, el "eco siempre parlante en medio del silencio" (p. 294). Blanchot se preguntará aún si esa palabra incesante que subsiste en el fondo del silencio es humana o divina, si es una palabra que no ha sido pronunciada y que pide serlo; él no dará una respuesta concreta, preferirá más bien preservar la ambigüedad, la indeterminación y lo inesencial de esa palabra, designándola como "la palabra secreta sin secreto" y sugiriendo que "cada uno, en medio de la soledad disimulada, busca una manera peculiar de convertirla en palabra vana, a ella que no pide otra cosa, ser vana y cada vez más vana, pues esta es la forma de su dominación" (1992, p. 246). Incluso en el silencio se está capturado por el exceso de esa palabra, pues "cuanto más silencio hay, más se transforma en rumor, [en] agitación perpetua de la calma" (2001b, p. 94). Para un ser solitario, como lo es el escritor según Blanchot, el silencio deviene el aterrador encuentro de lo que no se detiene; al borde de la zozobra o de la locura, aparecerá la necesidad de interrumpirlo.

Aquí emerge para el escritor otra exigencia, quizás la más apremiante: ¿cómo interrumpir tal palabra? Al respecto Blanchot da, a su modo, una respuesta paradójica: "el autor se expresa contra una palabra indefinida e incesante, sin principio ni fin, contra ella pero también con su ayuda" (1992, p. 276). Estas palabras van a resonar en lo que él dice a propósito del habla vacía de la voz de mando —el habla de la repetición imperiosa del hombre poderoso: el amo, el dictador - cuando afirma que es necesario que el escritor "le imponga el silencio", no con la responsabilidad de apaciguarla en él mismo, sino con la necesidad de reconducirla "hacia el silencio que está en ella" (p. 250). Por fuera de esta apreciación, cabe señalar que para Blanchot, en general, la exigencia de imponer silencio al murmullo incesante no sería posible más que a través de la "intimidad" del murmullo mismo; es necesario que el escritor entre "en una relación de intimidad con el rumor inicial [...] sólo a este precio puede imponerle silencio, oírlo en medio de ese silencio, y luego expresarlo, después de metamorfosearlo" (p. 248). Pero ¿en qué consiste esa especie de procedimiento imaginario a partir del cual el escritor decide entrar "en una relación de intimidad con el rumor inicial" para metamorfosearlo? Comprometiéndose primero a escuchar el silencio de lo que habla incesantemente, el escritor se expone a su desmesura para reconducirlo luego hacia su propio silencio y preservarlo así, silencioso, es decir, que en lugar de volverlo nuevamente una voz de mando o una palabra luminosa, él lo vaciará de todo poder, de toda unidad y de toda claridad, convirtiéndolo en una "palabra con la que nada puede ser dicho" (1987, p. 164); es ahí que se encuentra metamorfoseado ese rumor primigenio que subsiste en la vana profusión de palabras, alternando con el borramiento del poder para estar tan cerca como sea posible del silencio, en un afuera silencioso que sería el verdadero refugio contra la palabra incesante. 
Un escritor es aquel que impone silencio a esta palabra, y una obra literaria es, para quien sabe penetrar en ella, una rica morada de silencio, una defensa firme y una muralla alta contra esa inmensidad hablante que se dirige a nosotros apartándose de nosotros (1992, pp. 246-247).

Pero ¿en qué consiste entonces ese silencio? ¿Acaso un escritor podría dar muestras de un silencio verdaderamente más puro? La respuesta no puede ser categórica, pues si se tiene en cuenta el trasfondo paradójico del murmullo que subsiste en el silencio, no habría modo de considerar un silencio puro o un verdadero silencio. Si es contra lo indefinido y lo incesante de una "inmensidad hablante" que el escritor debe expresarse para hacer del silencio una morada, ese silencio tampoco sería el rechazo del habla, sino lo que "en la mínima habla, aún no se ha desarrollado en modos de hablar" (Blanchot, 1994, p. 162), es decir, "la voz que [aún] no ha dicho nada, que se despierta y que despierta" (2009, p. 41). Se trata de lo que Blanchot asocia al lenguaje poético, del cual dice que es una "palabra del comienzo" (p. 44) en donde la palabra misma es reenviada indefinidamente a su propio silencio, suspendida por el "silencio desnudo del pensamiento" (44), pero corriendo siempre el riesgo de ser nuevamente densificada por la impetuosidad y el anonimato de la "profundidad parlante, incesante, [de aquel] murmullo donde nada se deja oír" (44). El silencio del escritor designa la interrupción por la cual emerge una palabra diferente; pero habría que decir que debajo de ésta se hace escuchar aún la crepitación de lo incesante, como si a partir del silencio el escritor no hiciera más que recomenzar e intensificar el rumor inicial. Entonces, si la "palabra del comienzo" tiene lugar en la ocasión de una interrupción, esta interrupción no será definitiva, sino un recomienzo eterno, una pura discontinuidad: la designación de un límite transitorio a lo que se repite sin fin. El escritor sólo logra rebasar la palabra incesante redoblándola, repitiéndola hasta "esa palabra de más en que desfallece el lenguaje" (2008b, p. 441), esa palabra de más que no hace sino prolongar el rumor a través de aquella reiteración infinita de la escritura mediante la cual se busca "guardar silencio"; ese es el designio paradójico de quien escribe, respecto del cual dice Blanchot (1990, p. 105): "Guardar silencio, esto lo queremos todos, sin saberlo, escribiendo".

\section{El desobramiento: vorágine interminable de la ausencia de obra}

Acaba de exponerse lo que Blanchot reconoce como "las tres exigencias" del habla literaria: "lo incesante, lo discontinuo, la repetición" (2008b, p. 441). Estos tres movimientos son aparentemente disímiles, pero los tres juntos van a yuxtaponerse a la pretensión de una unidad o de un acabamiento definitivo, siendo envueltos por un movimiento más vasto: el desobramiento. En la perspectiva de Blanchot, la literatura comienza con la escritura, que si bien "hace obra de palabra", no obstante, "esta obra es desobramiento" (545), pues la decisión de comenzar a escribir no es sino la inmersión en ese juego insensato donde el recurso a la mediación de las palabras no conduce a una obra, sino a la producción de una ausencia indefinida 
que es, en primera instancia, ausencia de obra y que se aproxima a la experiencia de la locura en su profusión vana, en la imposibilidad de acabar:

Escribir es producir la ausencia de obra (la desobra). O también: escribir es la ausencia de obra tal como ella se produce a través de la obra y atravesándola. Escribir como desobra (en el sentido activo de esta palabra), es el juego insensato, el albur entre razón y sinrazón (545). ${ }^{1}$

Si la razón, en tanto que pensamiento de lo que es posible, excluye la locura como la imposibilidad misma, el desobramiento será la operación en la que se pone en cuestión la afirmación que identifica el pensamiento únicamente con lo que es posible, revelando una experiencia diferente donde el pensamiento "busca experimentarse más esencialmente como un poder sin poder" (255). El desobramiento es el exceso de la imposibilidad, la vana sobreabundancia donde "la realización del lenguaje coincide con su desaparición [y] la palabra misma no es sino la apariencia de lo que desapareció" (1987, p. 38). El desobramiento lleva el lenguaje literario a esa profundidad vacía donde el lenguaje mismo no es el poder de decir, pues no habla sino como ausencia:

Allí en donde no habla, ya habla; cuando cesa, persevera. No es silencioso porque, precisamente en él, el silencio se habla [...] Eso habla pero sin comienzo. Eso dice, pero no remite a algo qué decir, a algo silencioso que lo garantizaría como su sentido (43).

El lenguaje literario habla entonces como ausencia porque allí donde emerge nada comienza, nada se dice, mas siempre está en recomienzo, la oscilación de una errancia infinita en la cual el escritor se consagra a la prolongación de lo inacabado, deviniendo él mismo un errante sin lugar. El carácter incesante y errante de la escritura designa la exterioridad radical del exilio — eso que Blanchot concibe como "el afuera" - , teniendo lugar al interior del lenguaje literario y dejando al escritor extraviado, privado de toda intimidad, ausente de sí mismo.

Así, el desobramiento no es solamente el punto donde la escritura literaria se cumple en su propia desaparición, sino además el punto donde el escritor también desaparece. La vorágine interminable de la ausencia es la ley del desobramiento; la ausencia de obra en tanto que inacabamiento o recomienzo conduce al escritor a la errancia perpetua en la cual se encontrará perdido, borrado, liberado a la intimidad de un lenguaje que finalmente se vuelve un "afuera infinitamente distendido" (43).

\footnotetext{
${ }^{1}$ En cuanto a la locura como ausencia de obra, remitimos al artículo de Foucault titulado justamente "la locura, la ausencia de obra", donde escribe: "la locura no manifiesta ni cuenta el nacimiento de una obra (o de algo que con la ayuda del genio o de la suerte, hubiera podido convertirse en una obra); designa la forma vacía de donde viene esa obra, es decir el lugar donde no deja de estar ausente" (Foucault, 1999, p.276).
} 
Incluso si ya se ha formulado cómo a través del silencio el escritor busca forjarse una morada provisoria contra la inmensidad parlante del mundo, no hay que olvidar que ese silencio, donde recomienza el lenguaje literario, comporta aún el advenimiento apremiante de lo incesante. Entonces, una vez que el habla literaria entra en ese juego interminable, el escritor, que trata de sobrellevar las implicaciones de ello, no encontrará en la literatura una morada fija o definitiva; lo cual no significa que en consecuencia pudiese alcanzar cierto universalismo con el que obtendría el poder de hablar por todos, en nombre de un desinterés objetivo. Al respecto Blanchot expresa:

Si escribir es descubrir lo interminable, el escritor que penetra esa región no se adelanta hacia lo universal. No va hacia un mundo más seguro, más hermoso, mejor justificado [...] no descubre el hermoso lenguaje que habla honorablemente para todos. Lo que en él habla, es que de una u otra manera ya no es él mismo, ya no es nadie (1987, p.24).

Cuando un escritor se entrega a la producción de una obra, no encuentra en ella el refugio donde podría permanecer en su yo apacible y protegido, al abrigo de los escollos del mundo, sino que se verá expuesto a la amenaza que le viene de ese "afuera infinitamente distendido" en el que se experimenta la intimidad del lenguaje literario. El escritor no debe defenderse de esta amenaza, al contrario, debe entregarse a ella:

Esto exige la obra: que el hombre que escribe se sacrifique por la obra, que se convierta en otro, no que se convierta en algún otro, o sea, del viviente que era, en el escritor con sus deberes, sus satisfacciones y sus intereses, sino más bien en nadie, en el lugar vacío y animado donde resuena el llamado de la obra (Blanchot, 1992, pp. 242-243).

La obra no pide que el escritor se vuelva hacia sí mismo, sino hacia ese afuera del desobramiento en el cual lo determinante no tiene que ver con la afirmación del yo de quien escribe. Incluso si un escritor pudiese sentir la necesidad de conservar una relación consigo mismo -frente a la aversión que le haría experimentar esa exigencia de desprenderse de sí mismo en beneficio de la escritura y de la obra-, al continuar escribiendo entrará inevitablemente en una relación de exterioridad donde se pierde en el tiempo de lo interminable. Se trata de lo que Blanchot llama "el reino fascinante de la ausencia del tiempo" (1987, p. 25) y que, según él, se aproxima al tiempo sin tiempo del morir ${ }^{2}$ conformando el circulo donde se reúnen o se espejean estas dos afirmaciones: escribir para desaparecer, desparecer para escribir; "el escritor es entonces el que escribe para poder morir y que obtiene su poder de escribir de una relación anticipada con la muerte" (81).

\footnotetext{
${ }^{2}$ Es en medio de la fuerza asoladora, incesante y sin destino del desobramiento que el escritor cae en "la ausencia de tiempo, allí donde le es necesario morir de una muerte sin fin" (Blanchot, 1992, p. 243).
} 
Cuando se relaciona la alteración del tiempo propio de la escritura con el morir - la "muerte sin fin" —, no se trata de la muerte en tanto que acontecimiento definitivo o en tanto que destino, sino como experiencia de un desobramiento interminable: movimiento infinito de lo inacabado en el que escribir, así como morir, es un incremento de la ausencia. Entonces, si el escritor — sabiendo que debe desaparecer para poder escribir- es aquel que entra en una "relación anticipada con la muerte", esto significa que lo que él experimenta es la ausencia de fin, puesto que sabe que muere, pero que su muerte es indefinidamente prorrogada y que aún le es necesario consagrarse a la exigencia vana de escribirmorir.

En El espacio literario (1987), al referirse a la experiencia kafkiana de la escritura, Blanchot encontrará en esta reciprocidad entre escribir y morir la fuerza enigmática de la exigencia a la que debe responder un escritor:

Escribo para morir, para dar a la muerte su posibilidad esencial, por la que es esencialmente muerte, fuente de invisibilidad, pero, al mismo tiempo, sólo puedo escribir si la muerte escribe en mí, hace en mí el punto vacío donde se afirma lo impersonal (Blanchot, 1987, p.134).

La reciprocidad que habría entre escribir y morir es nombrada por Blanchot como "la inversión radical" que correspondería, además, a "la pérdida del poder de morir, la pérdida de la muerte como poder y como posibilidad" (217). Esta reciprocidad es igualmente pronunciada por el narrador de En el momento deseado quien dice: "iLa muerte! Pero, para morir, había que escribir, - iEl final! Y para ello, escribir hasta el final" (2006a, p. 43).

Ahora, aquella voluntad del escritor "para dar a la muerte su posibilidad esencial" no reenvía en Blanchot a la conciencia de la "muerte posible"; no se trata, como en Heidegger, de hacer de la muerte una posibilidad ${ }^{3}$ o una salida, aceptándola valientemente como lo que marca lo infranqueable y hacer así de ella la más apropiada posibilidad, aquella que permitiría habitar el mundo de una manera autentica. A esta imposibilidad que es la muerte habría más bien que responder con la insuficiencia que se afirma en el morir: un fin que no termina y que es la abertura hacia un porvenir indeterminado donde no hay ya esperanza de forjarse o de alcanzar una morada, o quizás sí, aquella otra morada que Blanchot denomina el Afuera, pero de la cual hay que subrayar siempre ese profundo carácter desobrante que está relacionado con la imposibilidad:

\footnotetext{
${ }_{3}^{3}$ Blanchot hace manifiesta su reticencia a la interpretación de la muerte como posibilidad en la siguiente frase: "que en el hombre todo sea posibilidad: esta afirmación exige primero que la muerte, sin la cual el hombre no podría formar un todo ni existir respecto a un todo, sea poder, sea posible, sea lo que hace todo posible, el todo posible" (Blanchot, 1987, p. 215).
}

Revista Filosofía UIS, Vol. 15, No. 1, enero-junio de 2016 pp. 145-162 
La imposibilidad es la relación con el Afuera y, dado que esta relación sin relación, es la pasión que no se deja dominar como paciencia, la imposibilidad es la pasión del Afuera mismo (2008b, p. 58).

Incluso si habría que reaprender a habitar el mundo para morar poéticamente en él (Heidegger, 1997), no por ello se tendría que desembocar necesariamente en la voluntad de edificar un remanso para escapar a la técnica que ha deshumanizado el mundo moderno. Citando a Lévinas, Blanchot advierte que "la técnica es peligrosa, pero menos peligrosa que los genios del Lugar" (2008a, p. 128.). La poesía tiene otras exigencias diferentes de la de morar el mundo, exigencias que provendrían justamente de la necesidad de salir del apego al Lugar y al Poder a través de la experiencia del Afuera y de lo imposible. La poesía no corresponde a un espacio del arraigo o de la intimidad; así un poeta sería "aquel para quien no existe siquiera un único mundo, porque para él sólo existe el afuera, el fluir del afuera eterno" (1987, p. 73). El designio del poeta está en el exilio y no en el arraigo a un lugar; él será "el eterno migrante" cuya única tarea es errar, entregándose a "la perpetuidad de lo inacabado" (1984, p. 120). Tal sería pues la promesa para el poeta: el extravío en el infinito de un exilio; Blanchot (1987) amplía esta perspectiva diciendo:

El poeta está en el exilio, está exiliado de la ciudad, exiliado de las ocupaciones regladas y de las obligaciones limitadas, de lo que es resultado, realidad palpable, poder. El aspecto exterior del riesgo al que la obra lo expone, es precisamente su apariencia inofensiva: el poema es inofensivo; esto quiere decir que quien a él se somete, se priva de sí mismo como poder, acepta ser arrojado fuera de lo que puede y de todas las formas de la posibilidad (211-212).

Además de la exigencia de acabar con el apego al Lugar, la poesía —articulada a la expresión más general de la palabra literaria — implica también la necesidad de acabar con el apego al Poder; ella se constituye como el reino de lo imposible, designando en el poeta la exigencia de algo que no se manifiesta en términos de un poder personal. A través del poeta habla lo que carece de poder, él es desposeído de lo posible para que la palabra se anuncie ella misma como impoder y para que en esa desnudez de la imposibilidad y del impoder pueda finalmente afirmarse la poesía como "palabra de poeta y no de amo" (1992, p. 40).

\section{La afirmación de la potencia neutra e impersonal de la obra}

Después de la ausencia de obra, la ausencia de autor, la ausencia de tiempo (o ausencia de fin), la ausencia de lugar, está también entonces la ausencia de poder. Parecería incluso que hay desobramiento porque a medida que la obra busca cumplirse es atraída "hacia ese punto en que ella pasa por la prueba de la imposibilidad" (243); es decir, que toda tentativa para constituir la obra no sería 
compresible más que en el punto elemental donde lo que existe es la desposesión de todo poder. Es más, Blanchot dirá que en la composición de la obra este estado elemental de impotencia puede corresponder a aquel de la inspiración, siendo ésta sin embargo ese punto donde ella falta, donde ella desaparecería deviniendo simultáneamente impotencia ${ }^{4}$. Quizás es Lévinas quien mejor ha comprendido este giro entre la inspiración y la impotencia, sugiriendo que la escritura sería "la inverosímil marcha de un poder que, llamado en cierto momento inspiración, «vira» en no-poder" (Lévinas, 2000, p. 38).

Por lo demás, es en este estado de impoder que se presenta el riesgo mayor para una obra literaria o artística, la cual podría zozobrar en la impotencia, dejando al escritor o al artista en un silencio o en una inercia insuperables; sin embargo, es justamente en este punto que la impotencia no coincide ya con la inspiración, pues mientras que ésta última se presentaría como lo que da lugar a la profusión de la escritura, la otra va a subsistir como la esterilidad que hay que afrontar para intentar transfigurarla en algo que podría comenzar a desarrollarse en lenguaje. Es así que para elaborar una obra literaria o artística hay que pasar por una experiencia en la cual debe enfrentarse la impotencia y lo imposible, no como fuente de inspiración, sino como afirmación: afirmación de la obra por la imposibilidad, afirmación tanto de la obra como de la imposibilidad. Para Blanchot, la obra de arte "no tiene poder, es impotente, y no porque sea el simple reverso de las variadas formas de la posibilidad, sino porque designa una región donde la imposibilidad ya no es privación sino afirmación" (1987, p. 198). Puede concluirse entonces que es en la experiencia de la imposibilidad de la obra que la vorágine de ausencia(s) propia al desobramiento corrobora toda su radicalidad; pero es también a partir de ahí que ella debe finalmente ser afirmada, transformando la imposibilidad en la potencia que constituye la obra.

Ahora bien, inmediatamente habría que matizar la naturaleza de esa potencia que se desprendería de tal transformación, pues para Blanchot el dominio de la literatura —y del arte en general — representa un muy singular tipo de poder que no tiene que ver con el orden de lo posible, sino que será caracterizado por él como una "potencia neutra" (1987, p. 29) ${ }^{5}$. Para describir la dinámica y la singularidad de esa potencia, hay que remitirse a las diferentes consideraciones que Blanchot hace a propósito de la relación entre literatura y poder. Una de las reflexiones que

\footnotetext{
${ }^{4}$ Según Blanchot, lo que han dejado entrever obras como las de Artaud, Hölderlin y Mallarmé es que "la inspiración es ante todo ese punto donde ella falta" (49). En este sentido también afirmará que "la obra es el movimiento que nos lleva hacia el punto puro de la inspiración de donde ella proviene y a donde parece que no puede llegar sino desapareciendo" (225).

${ }^{5}$ En diversas ocasiones Blanchot utiliza la expresión "potencia neutra" para referirse al "poder" de la literatura y del arte en general; además de aparecer en El espacio literario (1987, p. 29), dicha expresión también se encuentra en El libro que vendrá (1992, p. 224) o aún en el texto sobre Michaux "L'infini et l'infini" (1966, p. 80).
}

Revista Filosofía UIS, Vol. 15, No. 1, enero-junio de 2016 pp. 145-162 
más caracteriza su pensamiento literario es, precisamente, aquella de la escritura en tanto que poder de impugnación que se hace cargo de todas las fuerzas y las formas de disolución y transformación; es el movimiento que aproxima la literatura a la exigencia política. Preservando siempre el rechazo radical del poder, ese ímpetu contestatario de la literatura se encontrará intensificado —o más bien reducido - en la vorágine del desobramiento donde, enfrentando la imposibilidad de la obra, la literatura acaba también por impugnar el poder que subsistiría en ella misma. Se trata de aquella otra exigencia a la que debe responder la literatura y en la cual su poder de impugnación entra en tensión con la responsabilidad de borrar en ella todo rastro de poder para convertirse en una "potencia neutra" donde la impugnación se abre al infinito —a la "superabundancia vana de la inacción [el desobramiento]" (1987, p. 39)—; es así que la literatura, al igual que otras formas de arte, "es discusión infinita, discusión sobre sí misma y sobre otras formas de poder - y eso no en la simple anarquía, sino en la libre búsqueda del poder original que el arte y la literatura representan (poder sin poder)" (Blanchot, 2006b, p. 54).

En esa impugnación interminable, lo único que instituye la literatura es el movimiento de rechazo y desobramiento. Es en este sentido que Blanchot objeta la pretensión de relacionar la literatura con algo diferente a ella misma; y evita, sobre todo, incorporarla al dominio de los productos culturales — como si ella fuera sólo o prioritariamente una de las ocupaciones prestas a instituir la cultura-. Él no busca privilegiar el posible poder cultural que existiría en la literatura porque presiente el riesgo que ella corre de ponerse al servicio de otro poder que la subordinaría. En cambio, él persevera en la fuerza impugnadora y neutra de la literatura. Es así que en un artículo aparecido en 1965 e intitulado "Los grandes reductores", él va a presentar la singularidad de la "potencia neutra" de la literatura como una apuesta primordial, sugiriendo que ella es "contestación del poder establecido, contestación de lo que es (y del hecho de ser), contestación del lenguaje y de las formas del lenguaje literario, en fin, contestación de ella misma como poder" (2007b, p. 66). Y en 1981, hablando de un posible compromiso del escritor fuera de todo apego al poder de la cultura, expresará aún que la escritura literaria está "en busca de un no-poder que rechace la maestría [el dominio], el orden $y$, ante todo, el orden establecido, y prefiera el silencio a una palabra de absoluta verdad, contestando así y contestando sin cesar" (2006b, p. 137) ${ }^{6}$.

\footnotetext{
${ }^{6}$ Se trata de la respuesta aportada por Blanchot a un cuestionario titulado "Comprométase.. Comprométase nuevamente" destinado para el especial "literatura" de mayo de 1981 del Nouvel observateur. Debe añadirse que Blanchot expresó ese rechazo a la institución cultural durante los acontecimientos de mayo del 68 cuando escribía "la cultura es el lugar donde el poder siempre encuentra cómplices. Por medio de la cultura, recupera y reduce toda palabra libre. Hay que luchar contra esta complicidad de la cultura y mostrar que hay en la cultura una relación de posesión por el sentido y un uso de las fuerzas represivas funcionando independientemente del juego social" (103).
} 
En este combate contra la apropiación de la literatura por la cultura, Blanchot se abstiene incluso de atribuir a aquella el epíteto de "creación", una palabra que, según él, está demasiado cargada de ideas recibidas y de pretensiones; aunque se busque otorgar a la literatura una naturaleza o una fuerza creadora — mientras que la cultura se ocuparía únicamente de admitir o acoger lo que ya fue creado-, habría que preguntarse inmediatamente "iqué quiere decir crear?" y es evidente que desde el contexto del desobramiento difícilmente podría restringirse la literatura a un "acto de creación", pues:

Lo que crea siempre está en hueco [sustraído] en relación con lo que es y este ahuecado [esta sustracción] sólo hace más resbaladizo lo que es, menos seguro de serlo, y, a causa de ello, como atraído hacia una medida distinta, la de su irrealidad, en la que, dentro de ese juego de la diferencia infinita, lo que es se afirma escabulléndose [sustrayéndose] tras el velo del no" (2008b, p. 519).

En el pensamiento literario de Blanchot, el giro desobrante es siempre más esencial que toda característica creadora que se pretendiese asignar a la literatura; y si se pretendiera aún sugerir que el desobramiento es ya una manera de acoger o de sobrentender la fuerza creadora de la literatura, habría que aclarar entonces la singularidad de esa fuerza, pues ella proviene de la impugnación que la literatura preserva como la impetuosidad que la atrae hacia su propio borramiento y hacia la ausencia de obra, allí donde ella deja en falta lo que produce.

Ahora bien, Blanchot también se abstiene de catalogar la literatura como "nihilista", una denominación que le parece tan inoportuna como pretenciosa; él se cuida de concederle una determinación demasiado fuerte, sea asimilándola como "creación" o sea caracterizándola como "nihilista", y prefiere matizar la posible tendencia destructora de la literatura explicando que ella no se identifica con "la violencia de una negación tajante", pues la ausencia que ella produce a partir del desobramiento

está como en el medio en relación con lo "real", y esa borradura que viene de ella, que también está en ella como el movimiento que quisiera borrarla [...] no logra hacerla desaparecer, sino que más bien la afirma por esa desaparición, reconduciéndola hacia la extrañeza de lo que da origen y, a veces, siempre quizá, la deja convertirse a su vez en cosa, cosa llena de suficiencia (2008b, p. 519).

Al evitar el calificativo de creación y la caracterización nihilista de la literatura, Blanchot llegará a pensarla momentáneamente bajo la idea de origen; al margen del contexto teológico, él va a concebir el origen como la fuente del desvío mismo, como lo que se desvía incesantemente, remitiéndolo al sentido ambiguo de ese punto "donde todo surge y donde todo zozobra, el juego mismo de la diferencia indiferente entre Surgir y Zozobrar" (520). Es por eso que ya no se conformará con 
definir la noción de origen como la identidad o la esencia propia a la obra literaria; a fin de cuentas, el origen es también algo que se borra en sí mismo, oscilando entre la emergencia y el hundimiento en el vacío. Sin embargo, él retendrá del origen el signo de ese juego de divergencia y de diferencia. Aquí no se trata absolutamente de la búsqueda que afirmaría, por la intermediación de la obra, una diferencia individual o personal; la obra literaria sólo afirma ese desvío infinito en el que la diferencia es llevada hasta la indiferencia, pero sin dejar a ésta en una uniformidad definitiva, es decir, preservando la diferencia como lo que se sustrae indefinidamente. La diferencia liberada por la obra o por el desobramiento - la oscilación entre surgir y zozobrar - sólo afirma la neutralidad impersonal que ella es: la "cosa llena de suficiencia" que se sustrae a toda determinación y a toda instrumentalización, lo que en El espacio literario Blanchot llama "la soledad de la obra".

Es a partir de este juego de la diferencia infinita — la diferencia postergada indefinidamente - que toda distinción de la literatura será a su vez infinitamente diferida, escapando a ser fijada o unificada en una identidad y frustrando toda tentativa de definirla. De este hecho se podría concluir que ella siempre corre el riesgo de ser devorada por su propia indeterminación y de ser despreciada por un mundo que pide obras precisas y útiles, o que justamente termina asimilándola a causa de su carácter impreciso e inofensivo para ordenarla como una pieza más de la cultura burguesa. Sin embargo, aquí reaparece la otra exigencia del compromiso de la escritura literaria, porque si hay "formas de lenguaje donde se construye y habla el todo, palabra de universo, palabra de saber, del trabajo y de la salud", hay que presentir aún, al margen de éstas, "una palabra completamente otra que libera el pensamiento de ser siempre sólo un pensamiento con vistas a la unidad" (521), señalando otra dimensión diferente de la posibilidad y del poder ${ }^{7}$.

Se transita aquí por el perímetro de aquel doble movimiento expuesto por Blanchot: uno donde la literatura no busca ni el poder ni la unidad, otro donde ella expresa la voluntad de dar curso al error del infinito. Es en este segundo movimiento que lo que podría nombrarse como la "esencia" de la literatura se transforma en la "errancia" de la literatura — cuya apuesta es el Afuera-, una errancia en la que es llevada a girarse incesantemente hacia su propio cuestionamiento, encontrando así que su esencia es "escapar a toda determinación esencial, a toda

\footnotetext{
Según Blanchot, mientras el mundo más se afirme y se produzca bajo el horizonte y el blindaje del poder, más parece que el arte deba descender hacia el punto de lo imposible y del impoder, allí donde "lo posible se atenúa" y al arte le toca mantener aún "la inseguridad y la desventura de lo que escapa de toda percepción y de todo fin. El artista y el poeta han recibido la misión de recordarnos obstinadamente el error, de orientarnos hacia ese espacio donde todo lo que nos proponemos, todo lo que hemos adquirido, todo lo que somos, todo lo que se abre sobre la tierra y el cielo, retorna a lo insignificante, donde lo que se aproxima es lo no-serio y lo no-verdadero, como si a lo mejor surgiese de allí la fuente de toda autenticidad" (Blanchot, 1987, p. 221).
} 
afirmación que la estabilice o realice: ella nunca está ya aquí, siempre hay que encontrarla o inventarla de nuevo" (1992, p. 225). De este modo, aquel que pretendiese afirmarla en ella misma tan solo afirmaría la imposibilidad propia del desobramiento. Y si en esta conmoción de su propio cuestionamiento y de su huidiza esencia, la literatura no desemboca en una realidad definida y segura — de ahí que ella pueda ser motivo de decepción ${ }^{8}$ — , es porque la exigencia de la impugnación infinita la desvía incansablemente de toda determinación y de toda finalidad mediante una búsqueda que no se preocupa "de lo que ella es «esencialmente», sino que se preocupa al contrario de reducirla, de neutralizarla [con] un movimiento que finalmente le escapa y la [hace] descender hasta un punto en el que sólo parece hablar la neutralidad impersonal" (224).

En esta exigencia interminable de la literatura, lo que trata de indicarse es que ella tiene al menos el valor de no desear el poder, de no ser un lenguaje de determinación o de señorío, retirándose discretamente después de descubrir que su apuesta no tiene que ver "ni con la inmortalidad ni con el poder ni con la gloria" (2008b, p. 486). Pero para ello quizá deba pasar mucho tiempo; para ello es necesario que alguien, mediante el silencio y la escritura, haga sensible la separación que hay entre él y lo que se dice, y así "las palabras deben caminar durante mucho tiempo. Caminar el tiempo suficiente para borrar sus huellas y sobre todo la presencia autoritaria de un hombre dueño de lo que debe decirse" (418).

Es a partir de Blanchot que se puede afirmar entonces que la exigencia infinita de la literatura no prueba nada ni a nadie, dejando resonar únicamente el movimiento infinito del desobramiento. Con tal movimiento, él abrió para la literatura un horizonte diferente de aquel de lo posible, un horizonte en el cual el escritor entrega todo el poder a la "potencia neutra" del lenguaje que, en lugar de concederle la posibilidad de una dominación, lo lleva más bien a ser atravesado, alterado por esa potencia que hace de él mismo alguien anónimo y sin poder, que lo hace deslizarse hacia la fisura inconmensurable del Afuera: el lugar reservado al borramiento y la desapropiación, allí donde cesa toda forma de autoridad.

\section{Epílogo}

Como se advirtió en la introducción, Blanchot nunca buscó elaborar una nueva teoría del poder o yuxtaponer a la comprensión del poder otra perspectiva, que como en el caso particular de Foucault, buscaría afirmar la simultaneidad y la variación de múltiples redes y relaciones de poder. Lo que deja como reto el pensamiento de Blanchot es la búsqueda de un espacio otro y una exigencia otra donde lo que se manifiesta es lo imposible y la condición de impoder que de ahí

\footnotetext{
8 Blanchot incluso aceptará que "la literatura está quizá hecha esencialmente para decepcionar" (2008b, p.520).
} 
se desprende; un impoder que no sería la mera negación del poder, sino además la afirmación del desobramiento y de la potencia neutra de la escritura: lo que no deja la posibilidad de una apropiación o de una unificación final, profundizándose en un movimiento incesante de discontinuidad.

A partir del pensamiento literario de Blanchot queda la exigencia de una ruptura radical con todo lo que quiere instituirse como poder. Este indicio de lo que bien podría considerarse como "pensamiento del afuera", es resguardado en su reflexión sobre la literatura, desde la cual, al ponerse en entredicho que todo sea posible, emerge otra exigencia tendiente a responder a lo imposible e implicando también un empeño en la exploración de otras formas o espacios en donde no opera el poder. Esa reflexión, que estaría más próxima a un lenguaje poético, es también correlativa a un rechazo a la individualidad o intimidad del yo, afirmando la búsqueda de un Afuera en el que sólo persiste el destino de tener que errar y errar sin la esperanza del arraigo en un lugar — con el que se pretendería forjar y morar el mundo- ; esta búsqueda del Afuera está a su vez insondablemente envuelta por una imposibilidad que hace que nunca se esté verdaderamente Afuera, llevando a la obsesión de tener que seguir buscando y distendiendo los límites, cual vorágine interminable que en su movimiento desobrante sólo afirma la potencia de lo inacabado. La búsqueda incesante del Afuera coincide con la exigencia de una "potencia neutra" que impele a una paciente efracción con la cual se posterga y se siguen extendiendo indefinidamente los límites, ahondando en una experiencia desestructurante en la que la diferencia no se aclara, sino que se difiere, se re-parte indefinidamente $\varphi$

\section{REFERENCIAS}

Blanchot, M. (1966). "L'infini et l'infini". Cahiers de L'Herne, (8), 73-87.

Blanchot, M. (1984). "La parole ascendante ou Sommes-nous encore dignes de la poésie?" En “Kozovoï, Hors de la colline” (pp.119-127). París: Hermann.

Blanchot, M. (1987). El espacio literario. Madrid: Editora Nacional.

Blanchot, M. (1990). La escritura del desastre. Caracas: Monte Ávila editores.

Blanchot, M. (1992). El libro que vendrá. Caracas: Monte Ávila Editores.

Blanchot, M. (1994). El paso (no) más allá. Barcelona: Paidós.

Blanchot, M. (2006a). En el momento deseado. Madrid: Arena Libros.

Blanchot, M. (2006b). Escritos políticos. Buenos Aires: Libros del Zorzal. 
Blanchot, M. (2007a). La parte del fuego. Madrid: Arena Libros.

Blanchot, M. (2007b). La Amistad. Madrid: Trotta.

Blanchot, M. (2008a). Ecrits politiques. Paris: Gallimard.

Blanchot, M. (2008b). La conversación infinita. Madrid: Arena Libros.

Blanchot, M. (2009). Una voz venida de otra parte. Madrid: Arena Libros.

Foucault, M. (1999). Entre Filosofía y literatura. Barcelona: Paidós.

Heidegger, M. (1997). Conferencias y artículos. Barcelona: Serbal.

Lévinas, E. (2000). Sobre Maurice Blanchot. Madrid: Trotta. 